\title{
Mucormycosis Following COVID-19 Infections: an Insight
}

\author{
Srijit Das ${ }^{1}$. $\cdot$ Subhra Dhar ${ }^{2}$
}

Received: 28 May 2021 / Accepted: 3 July 2021/Published online: 10 July 2021

(c) Association of Surgeons of India 2021

Coronavirus disease 2019 (COVID-19) is caused by severe acute respiratory syndrome coronavirus 2 (SARS-CoV-2). The second wave of COVID-19 pandemic resulted in increased mortality and morbidity. Treatment becomes more challenging with the absence of facts in conventional textbooks. Multisystem inflammatory syndrome and autoimmune conditions were described by the Centre for Disease Control and Prevention [1]. The individual's immune system is vulnerable to many fungal infections. Fungal infections associated with COVID-19 include aspergillosis, candidiasis, mucormycosis, or cryptococcosis. Recently, there was an increase in the incidence of mucormycosis, colloquially called black fungus because of the gangrenous changes in the tissue. The term black fungus is a misnomer because Mucorales are not dematiaceous fungi [2].

Mucormycosis occurs in six different forms, i.e., rhinocerebral, pulmonary, cutaneous, gastrointestinal, and disseminated, and the most frequent sites of infection include pulmonary, rhinocerebral, cutaneous, and disseminated [3]. It was thought that there might be higher chances of mucormycosis in COVID-19 individuals who were diabetic and treated with corticosteroids. Interestingly, many COVID-19 patients who were non-diabetic and never used steroids also contracted the infection. Hence, it will be interesting to see whether COVID-19 itself possesses a risk factor by modifying the immunological markers. Prolonged hospital stay with mechanical intubation may also increase the chances of mucormycosis. Indiscriminate and prolonged use of antibiotics may be responsible for increased susceptibility to fungal infections [4]. Oxygen therapy and the duration of therapy may be responsible for mucormycosis.

Srijit Das

drsrijit@gmail.com

1 Department of Human \& Clinical Anatomy, College of Medicine \& Health Sciences, Sultan Qaboos University, P.O. Box 35, Al-Khoud, Muscat 123, Sultanate of Oman

2 Wizdermpathlab, 1/503 Gariahat Road, Kolkata 700068, West Bengal, India
Mucor is a saprophytic fungus present in the soil, air, food, and even in the nasal mucosa of the healthy individual as a commensal [5]. The diagnosis of mucormycosis may be missed or misdiagnosed and it may be life threatening. Mucormycosis is a severe infection and it may destroy the local vasculature which makes the treatment with antifungal agents becomes more challenging. Mucormycosis is treated with different drugs such as amphotericin $\mathrm{B}$, isavuconazole, and posaconazole. At times, surgical debridement or even amputations are needed.

It was known earlier that zinc inhibits growth of mucormycosis but, interestingly, recent studies reveal that antimicrobials act by reducing the intracellular level of zinc and such has been seen in the case of the drug Atovaquone which is used for treatment of Candida albicans, Aspergillus sp., and Fusarium sp. [6]. Fungi are known to be susceptible to zinc deficiency in vitro. Their growth is reduced by use of zinc chelators like clioquinol, phenanthroline, etc. [7]. Proper understanding of the zinc transporters, zinc-responsive transcription factors of fungi, and zinc-binding proteins in the cytosol and organellar compartment may be important. Excess zinc level could also displace other redox-active metals in the body. It cannot be refuted that other proteins in the cytosol also compete for zinc binding. The mucormycosis epidemic exposed the healthcare system including lack of practice of evidence-based medicine, and poor medical practice across which led to indiscriminate steroid/antibiotic use in COVID-19 and beyond. In future studies, researchers may look at other possible risk factors including monitoring appropriate dose of steroids and studying the incidence of infections in rural and urban patients.

\section{Declarations}

Conflict of Interest The authors declare no competing interests. 


\section{References}

1. Centre for Disease Control and Prevention. Retrieved from website https://www.cdc.gov/coronavirus/2019-ncov/long-term-effec ts.html on 27.5.2021

2. Ravankar SG, Sutton DA (2010) Melanised fungi in human disease. Clin Microbiol Rev 23:884-928. https://doi.org/10.1128/ CMR.00019-10

3. Petrikkos G, Skiada A, Lortholary O, Roilides E, Walsh TJ, Kontoyiannis DP (2012) Epidemiology and clinical manifestations of mucormycosis. Clin Infect Dis 54(Suppl 1):S23-34. https://doi. org/10.1093/cid/cir866

4. Perlroth J, Choi B, Spellberg B (2007) Nosocomial fungal infections: epidemiology, diagnosis and treatment. Med Mycol 45:321346. https://doi.org/10.1080/13693780701218689

5. Elinav H, Zimhony O, Cohen MJ, Marcovich AL, Benenson S (2009) Rhinocerebral mucormycosis in patients without predisposing medical conditions: a review of the literature. Clin
Microbiol Infect 15:693-697. https://doi.org/10.1111/j.14690691.2009.02884.x

6. Clark HL, Minns MS, Sun Y, de Jesus T, Ghannoum MG, Pearlman E (2018) Atovaquone impairs growth of Aspergillus and Fusarium keratitis isolates by modulating mitochondrial function and zinc homeostasis. Invest Ophthalmol Vis Sci 59:1589-1598. https://doi.org/10.1167/iovs.17-22585

7. Laskaris P, Atrouni A, Calera JA et al (2016) Administration of zinc chelators improves survival of mice infected with Aspergillus fumigatus both in monotherapy and in combination with caspofungin. Antimicrob Agents Chemother 60:5631-5639. https://doi. org/10.1128/AAC.00324-16

Publisher's Note Springer Nature remains neutral with regard to jurisdictional claims in published maps and institutional affiliations. 